\title{
An Investigation on Mechanical Properties and Durability of Concrete Containing Silica Fume and Fly Ash
}

\author{
A. Sadr Momtazi ${ }^{\mathrm{a}}$, B. Tahmouresi ${ }^{\mathrm{b}}$, R. Kohani Khoshkbijaric \\ ${ }^{a}$ Associate Professor of Civil Engineering Faculty, Guilan University, Iran. \\ ${ }^{b}$ M.Sc Student of Civil Engineering, Guilan University, Iran. \\ ${ }^{c}$ Ph.D Candidate of Civil Engineering, Guilan University, Iran. \\ Received 9 March 2016; Accepted 19 May 2016
}

\begin{abstract}
Nowadays pozzolans are used vastly in civil projects. Pozzolan is a natural or artificial material containing active silica that increase the strength and improves some properties of concrete. In this survey for investigating some important properties of concrete, silica fume and fly ash was used in replacement of cement in different weights. Concrete compositions were made with water-cement ratio of 0.45 and cured under the same conditions. The main focus of this survey is to investigate the individual and combined effect of using Pozzolan on mechanical properties, permeability and shrinkage of concrete. The mechanical properties of concrete in compressive and bending strength at the age of 7, 28 and 90 days, were evaluated. Permeability was investigated with the water absorption test. The drying shrinkage of concrete was monitored for 90 days. Scanning Electron Microscopy (SEM) images was used in concrete cement based matrix morphology. The results showed that the addition of pozzolan increases the mechanical strength and reduce permeability and increase the drying shrinkage in some mixtures.
\end{abstract}

Keywords: Silica Fume; Fly Ash; Mechanical; Permeability, Compression, SEM.

\section{Introduction}

Energy crises and the need to save the energy-making materials in producing productions like cement has caused to make a full-scale effort in producing economically and improving the quality in global scale. One of the effective steps toward this problem is using both natural and artificial Pozzolanic materials in cement. Using these materials as a replacement to a portion of cement, not only reduces the price of concrete but also improves the properties of fresh and hardened concrete. By far many researches are done worldwide on different kinds of Pozzolans. As an example, micro silica and fly ash can be named that have proper Pozzolanic characteristics and in increasing the strength and durability of concrete have an effective role. Knowing the fact that permeability and shrinkage are the key properties of concrete in studying its long-term behavior and they have a tight relation with its durability, using mineral additives and industrial Pozzolanic residues in order to improve the long-term functionality and increase the strength of concrete was the research subject of many experts in this field and is resulted to vast industrial application of some of these materials. The researches have shown that replacement of a portion of cement with some Pozzolanic additive materials decreases the hydration temperature and its resulting crack and also reduces the shrinkage. Stable construction with the aim of saving energy, resources and costs and also reducing the destructive environmental effects are some advantages of using these kinds of additives [1-6].

Silica fume (SF) that is of industrial additives is actually dust emissions from the chimneys of factories producing silicon and silicon alloys, such as Ferrosilice in electric arc furnaces. Its reaction with massive and high porosity limestone crystals and converting them to calcium silicate hydroxide gel C-S-H improves the bond between cement

*Corresponding author: behzad.tahmouresi@gmail.com 
paste and aggregate that is used as a cement replacement in concrete production [7-9]. Bhanja and Sengupta investigated the effect of silica fume on concrete tensile strength, therefore different water-cement ratio ( 0.26 to 0.42$)$ as well as replacement of silica fume with cement at different levels ( 0 to $30 \%)$ were considered[10]. Their results showed that the presence of silica fume in the mixture caused a significant increase in tensile and compression strength. Fly ash is a material with very fine particles (particles as cement) that is obtained from the waste of combustion of coal powder in thermal power plants [11-13]. The effect of FA, GGBFS and SF as a supplement mixture of cement in binary, ternary and quaternary combination was investigated by Gesoglu and Ozbay on fresh and hardened self-compacting concrete properties [14]. They reported that a ternary mixture of cement with FA and SF has higher compressive strength compared to the binary mixture with the same amount of replacement. Shrinkage is the volume change caused by losing the buried water in concrete due to evaporation as a result of being exposed to dry environments. This evaporation depends on relative humidity, temperature, water-cement ratio, size and shape of the sample. Shrinkage of concrete with constant water-cement ratio of 0.35 was examined by Katri and Sirivivatnanon [15]. It was found that replacement of $10 \%$ of the cement with silica fume increases the shrinkage at early ages and reduces it in the long term. Sadr and Fasihi reported an increase in shrinkage in a study on the silica fume cement composites and nano silica [16]. Also in replacement of slag with cement due to the small amount of calcium hydroxide, this effect reduces to a large extent compared to replacement of silica fume with cement. Also, according to investigations of .Jianyong and Yan on three different kinds of concrete containing silica fume and slag individually and combinationally, with water-cement ratio of 0.26 , it was shown that drying shrinkage at early ages was the same [17]. After 28 days, the amount of shrinkage changed so that at the age of 180 days, the amount of control mix design, $30 \%$ of slag and the combination of $10 \%$ silica fume with $30 \%$ slag were 220, 96 and 127 micrometers, respectively. Calcium hydrate formation due to pozzolanic reaction of mineral additives that have been replaced by cement can be the reason to reduce the shrinkage. Knowing the permeability of concrete for structures that are subject to severe environmental change such as melting, freezing and chemical attacks are of great importance. Thus, molecular and ion permeability of concrete, acts a special role in being affected by the environment and the loading capacity of the structure during decades of its age. Hooton studied the permeability of concrete containing silica fume and stated that permeability decreased with the addition of silica fume [18]. Permeability of control mixture was $1.8 \times 10^{-14}$ meters per second while for the concrete mixture containing $10 \%$ silica fume, it was less than $1 \times 10^{-17}$ meter per second.

In this study, the investigation on some of the important properties of concrete containing silica fume and fly ash as a cement materials replacement in different quantities were discussed. Concrete mixtures were made with watercement ratio of 0.45 . The main focus of this study was to evaluate the effect of individual and combined use of pozzolan on mechanical properties, permeability and shrinkage of the concrete. Permeability was investigated with the water absorption test. The drying shrinkage of concrete was monitored for 90 days. The mechanical properties of concrete in compressive and bending strength at the age of 7, 28 and 90 days, were evaluated. Scanning Electron Microscope (SEM) images was used in concrete cement based matrix morphology. The results showed that the addition of pozzolan increases the mechanical strength and reduce permeability and increase the drying shrinkage in some mixtures.

\section{Experimental Program}

\subsection{Materials}

In this study, type 1-425 Khamse Zanjan cement in accordance with ASTM C150 standard was used, silica fume of Iran Ferrosilicon company in accordance with ASTM C1240 standard and fly ash in accordance with ASTM C618 standard in mix design was used. Its physical and chemical properties are given in tables 1 and 2, respectively. In order to achieve proper slump $(70 \pm 20)$ super plasticizer with the brand of P10-3R was bought from the Shimi Sakhteman Company. Aggregates used to produce the mixture of crushed gravel with a maximum size of $19 \mathrm{~mm}$ and a density of $2650 \mathrm{~kg} / \mathrm{m} 3$ and natural sand with density of $2600 \mathrm{~kg} / \mathrm{m} 3$ that was in accordance with the ASTM C33 standard.

Table 1. Physical properties of cementitious materials

\begin{tabular}{ccccc}
\hline Item & $\begin{array}{c}\text { Specific surface } \\
\left(\mathbf{c m}^{2} / \mathbf{g r}\right)\end{array}$ & $\begin{array}{c}\text { Density } \\
\left(\mathbf{g r} / \mathbf{c m}^{\mathbf{3}}\right)\end{array}$ & $\begin{array}{c}\text { Initial setting } \\
\text { time (min) }\end{array}$ & $\begin{array}{c}\text { Final setting } \\
\text { time (min) }\end{array}$ \\
\hline Cement & 3100 & 3.15 & 110 & 170 \\
Silica fume & 6500 & 2.2 & - & - \\
Fly Ash & 3670 & 2.5 & - & - \\
\hline
\end{tabular}


Table2. Chemical composition of cementitious materials (\%)

\begin{tabular}{cccccccccc}
\hline Item & $\mathbf{C a O}$ & $\mathrm{SiO}_{2}$ & $\mathrm{Al}_{2} \mathrm{O}_{3}$ & $\mathrm{Fe}_{2} \mathrm{O}_{3}$ & $\mathrm{MgO}$ & $\mathrm{K}_{2} \mathrm{O}$ & $\mathrm{Na}_{2} \mathrm{O}$ & $\mathrm{SO}_{3}$ & L.O.I \\
\hline Cement & 64.37 & 21.08 & 5.36 & 3.64 & 2 & 0.82 & 0.5 & 2.1 & 0.9 \\
Silica Fume & 1.5 & 90 & 1 & 2 & 2 & 0 & 0 & 0 & 3.5 \\
Fly Ash & 8.6 & 59.3 & 23.4 & 4.8 & 0.6 & - & 3.2 & 0.1 & - \\
\hline
\end{tabular}

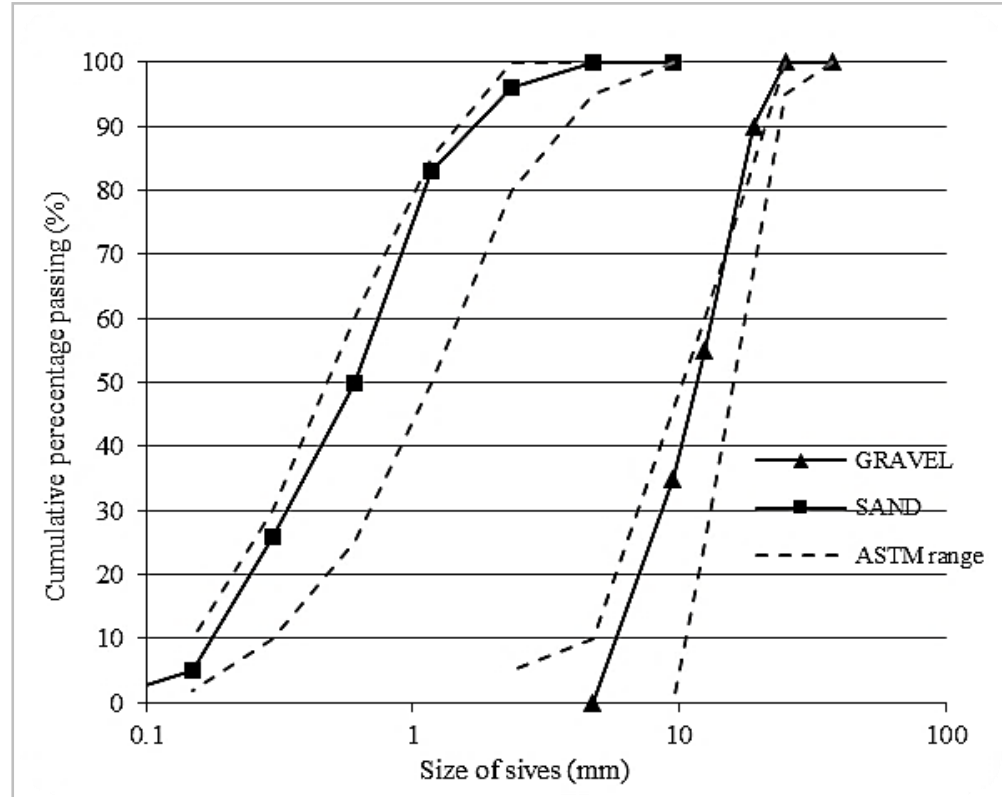

Figure 1. Particle size distributions of aggregate

\subsection{Preparing and curing of mix designs}

First, aggregate in state of saturated surface dry (SSD) was poured in the mixer. Then cement powder materials and some water is added and the remaining water was gradually added to the mixture. Mixing time was between three to four minutes. Concrete compacting was achieved in the laboratory using a vibrating table. Mix Designs of this research are shown in Table 3. According to ASTM C192, after 24 hours of curing the specimens in the mold with a plastic cover, they were exported and placed in a saturated lime water laver with standard temperature until the day they were tested.

Table 3. Mix designs

\begin{tabular}{cccccccc}
\hline $\begin{array}{c}\text { Mix Design } \\
\text { Name }\end{array}$ & W/B & Cement & $\begin{array}{c}\text { Silica } \\
\text { fume }\end{array}$ & Fly Ash & Fine agg & $\begin{array}{c}\text { Coarse } \\
\text { agg }\end{array}$ & S.P \\
\hline control & 0.45 & 400 & 0 & 0 & 944 & 871 & 0.7 \\
F15 & 0.45 & 340 & 0 & 60 & 939 & 867 & 0.45 \\
F25 & 0.45 & 300 & 0 & 100 & 935 & 863 & 0.3 \\
S10 & 0.45 & 360 & 40 & 0 & 937 & 865 & 1.2 \\
S25 & 0.45 & 300 & 100 & 0 & 925 & 854 & 1.45 \\
S5F5 & 0.45 & 360 & 20 & 20 & 939 & 867 & 0.9 \\
S10F5 & 0.45 & 340 & 40 & 20 & 935 & 863 & 1.1 \\
S15F10 & 0.45 & 300 & 60 & 40 & 929 & 857 & 1.2 \\
\hline
\end{tabular}

B: Binder, F: Flay Ash, S: Silica Fume, SP: Superplasticizers.

\section{Results and Discussion}

\subsection{Compressive Strength Test}

The tests were executed at the ages of 7, 28 and 90 days on the $10 \mathrm{~cm}$ cubic samples. The results are shown in Figure 2. According to the results, the increase in strength over time can be observed in all samples. In samples containing fly ash with cement, compressive strength in comparison with control mix design is not increased at the age 
of 7 and 28 day. At the age of 7 and 28 the control mix design showed the maximum strength but at 90 days age, the FA15 mix design had $40 \mathrm{MPa}$ of compressive strength that showed $17.6 \%$ enhancement compared to control mix design. Also at the age of 90 days, all samples showed more strength with respect to control mix design. In individual mixtures, combination of silica fume and cement, compressive strength at ages of 28 and 90 days significantly increased, so this increase is respectively $29 \%$ and $19 \%$. According to studies of some researchers $[15,19]$ the presence of silica fume due to pozzolanic reaction with calcium hydroxide in the cement paste and calcium silicate hydroxide gel formation causes enhancement in the strength. Silica fume can improve the microstructure and mechanical strength of concrete. Ultrafine particles of fume by filling voids in the cement paste and having reaction with the calcium hydrates in the paste, improve compacting and physical and chemical properties of concrete [20]. According to the results, the rate of increase in compressive strength in mix designs containing fly ash in comparison with mix designs containing silica fume individually is less. The slower pozzolanic reaction of fly ash could cause this issue. In combinatorial mix designs increasing the amount of pozzolan caused improvement in strength and at older ages, it is more considerable.

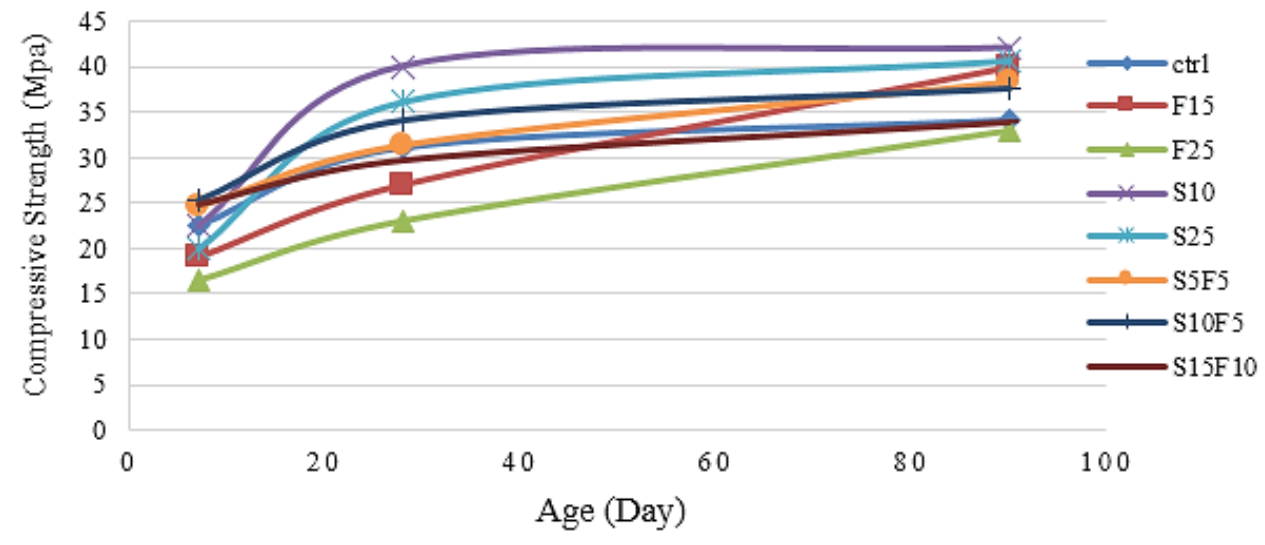

Figure 2. Compressive strength of concrete mixtures

\subsection{Flexural Strength Test}

The test was done according to ASTM C78 for three points on cubic specimens with $7 \times 7 \times 28 \mathrm{~cm}$ dimensions at ages 7, 28 and 90 days. Figure 3 shows the results of flexural strength in different replacement percentages of silica fume and fly ash individually and in combination. According to the results, the addition of pozzolans increased flexural strength. In the mixtures containing up to $15 \%$ of fly ash flexural strength increased and after that it decreased and the maximum of flexural strength values at 28 and 90 days was 7.54 and $7.8 \mathrm{MPa}$ that related to F15 mix design. It seems silica fume has more impact on the flexural strength so that in all of the replacement percentages the flexural strength is higher than control mixture at all ages. In mixtures containing silica fume individually maximum amount of flexural strengths at the age of 7,28 and 90 days, respectively were 7.12, 10.14 and $11 \mathrm{MPa}$ and they were related to S10 mix design which has respectively $11 \%, 36 \%$ and $44 \%$ improvement is strength with respect to control mix design. Results of combinatorial mix designs also shows an increase in flexural strength compared to the control mix design.

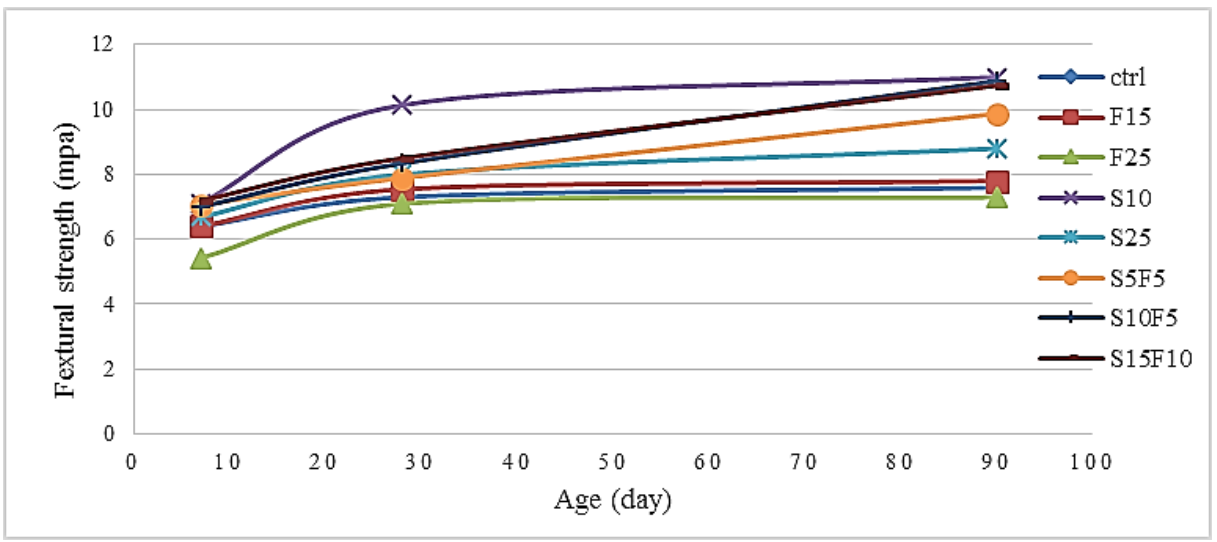

Figure 3. Flexural strength of concrete mixtures 


\subsection{Final Water Absorption Test}

The water absorption was tested according to ASTM C642 standard on cubic samples at the age of 28 and 90 days. The importance of this test it is that its results indicates the volume of capillary and large pores in a cement composite that is an important criterion in assessing the influence of destructive ions. The results of water absorption test were determined based on the average results of three samples are shown in Figure 4. The results show that by increasing the amount of pozzolanic materials replacement of cement, water absorption reduction of concrete is significant. The addition of fly ash up to $10 \%$ caused $18.5 \%$ reduction in water absorption. Also with increasing replacement of silica fume up to $25 \%$, water absorption had downward trend up to $46 \%$. Compared with fly ash, silica fume can impressively reduce the amount of water absorption and by increasing the replacement rate, water absorption is reduced. In mixed pozzolan mixtures in high percentage of silica fume and fly ash water absorption reduction is clear.

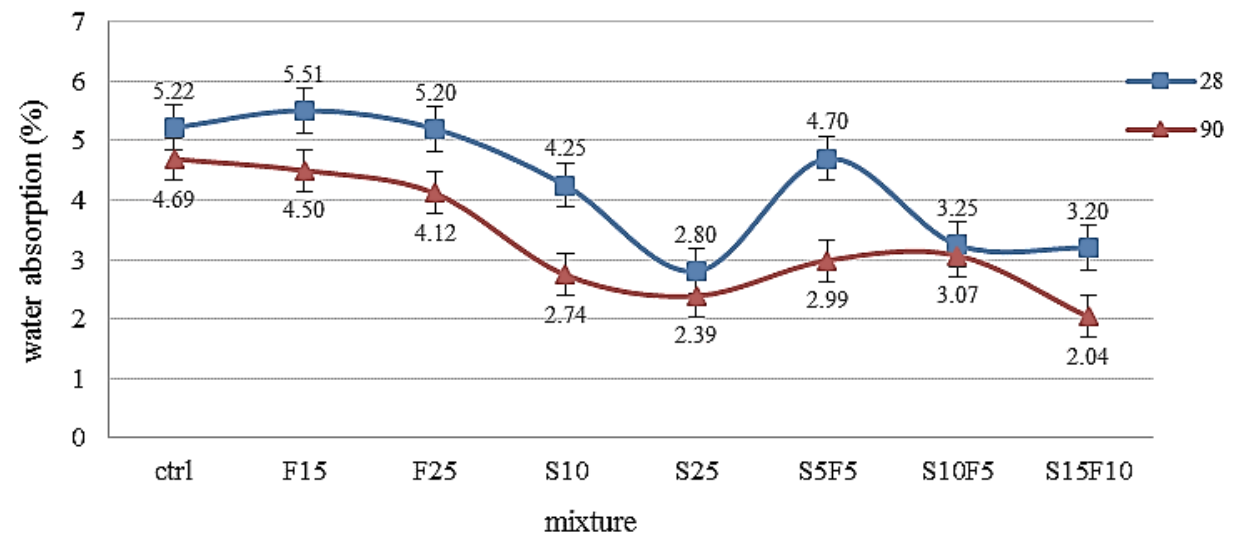

Figure 4. Water absorption of concrete mixtures

\subsection{Morphology}

Scanning Electron Microscope (SEM) is an effective way to evaluate the morphology of hydrated cement-based products. According to Figure 5, some of the pores caused by the crystallization of excess lime are clearly visible and due to the absence of mineral additives, the porosity of the paste is obvious. It indicates that the paste matrix is not significantly compressed. In comparison with the control mixtures, the mixtures containing pozzolans showed more uniformity, compacting and improve interfacial transition zone (ITZ). The concrete containing $10 \%$ silica fume and $15 \%$ fly ash, showed most uniform microstructure and compacting in cement matrix.

\subsection{Shrinkage Test}

Shrinkage was tested according to ASTM C157 on the cubes with $7 \times 7 \times 28 \mathrm{~cm}$ dimensions. The specimens extracted from the mold and after 24 hours under ambient conditions for drying shrinkage by the available strain gauge (with an accuracy of a thousandth of a millimeter) were evaluated for 90 days. The average results of measurements were performed on two samples. Shrinkage has a great importance to study the long-term durability and performance of concrete structures. In fact, the importance of shrinkage is that it can be a source of cracking, reducing resistance, redistribution of stress and in some cases also led to the destruction of the structure. The results of shrinkage are shown in Figure 5. The results indicated that the addition of silica fume is significantly affected drying shrinkage of concrete. The greatest change in the amount of shrinkage is related to mixtures containing silica fume. The shrinkage values have increased compared to the control mixture. The effect of silica fume can be a cause of this issue. The use of mineral additives in concrete mixture changes pore microstructure and geometry, change in capillary pore structure causes a change in shrinkage, Using silica fume increase drying shrinkage of concrete and it can be because of the pozzolanic behavior of silica fume [21]. The mixtures containing fly ash showed reduction in the rate of shrinkage compared to control mix design. During first days the changing rate of S10 and S25 mixtures was more than other mixtures that indicates extreme pozzolanic activation of silica fume on early ages. 


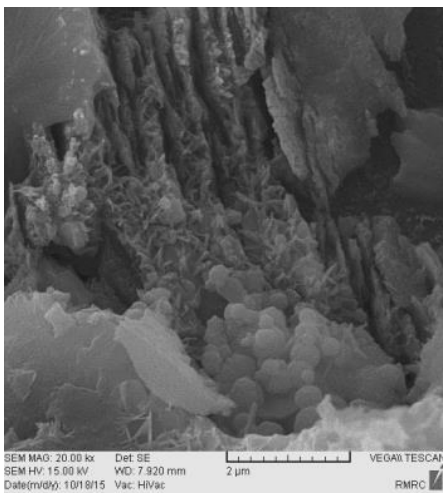

(a)

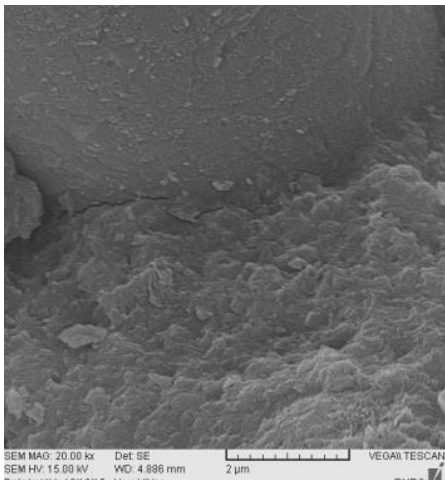

(d)

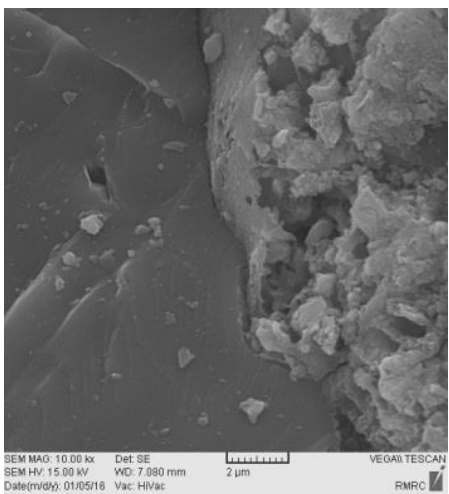

(g)

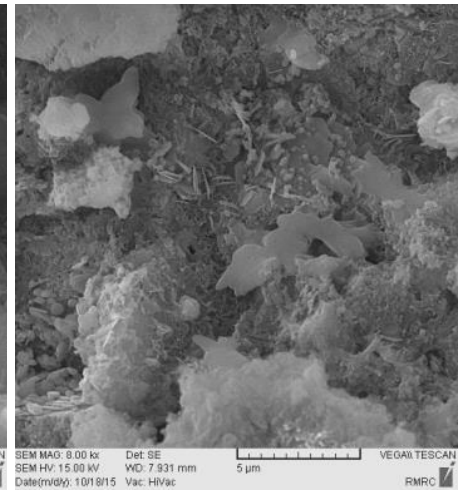

(b)

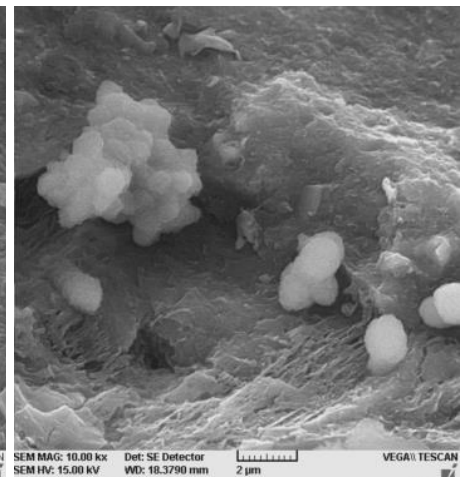

(e)

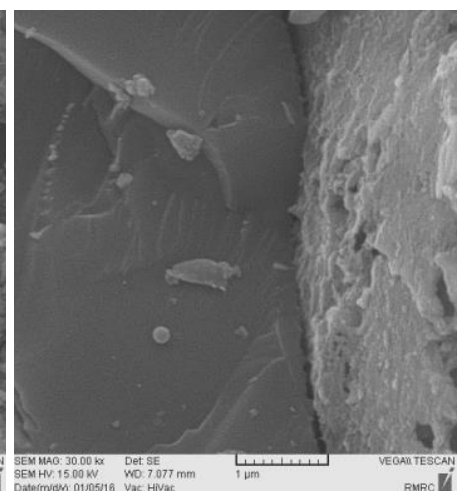

(h)

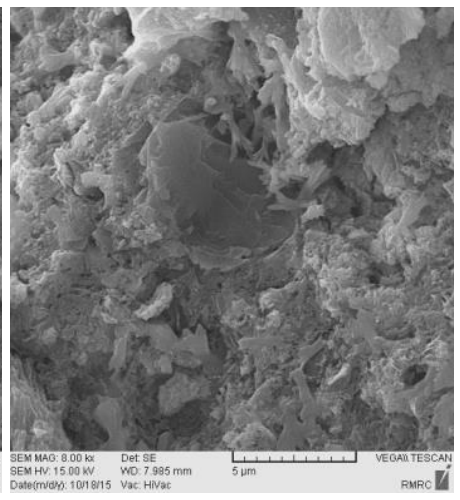

(c)

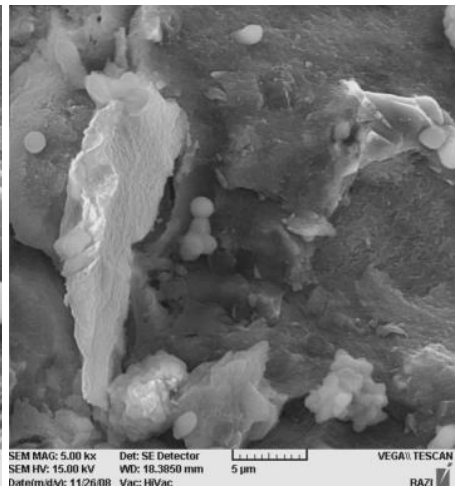

(f)

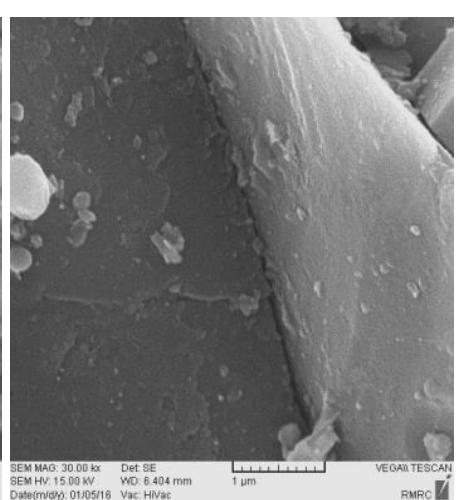

(i)

Figure 5. Effect of pozzolanic additives on the microstructures of concrete after 90 days. (a) to (c): cement paste of Control sample, (d) to (f): cement paste of Silica fume $(10 \%),(\mathrm{g})$ : concrete sample of control, (h): concrete sample of F15, (i) concrete sample of S10

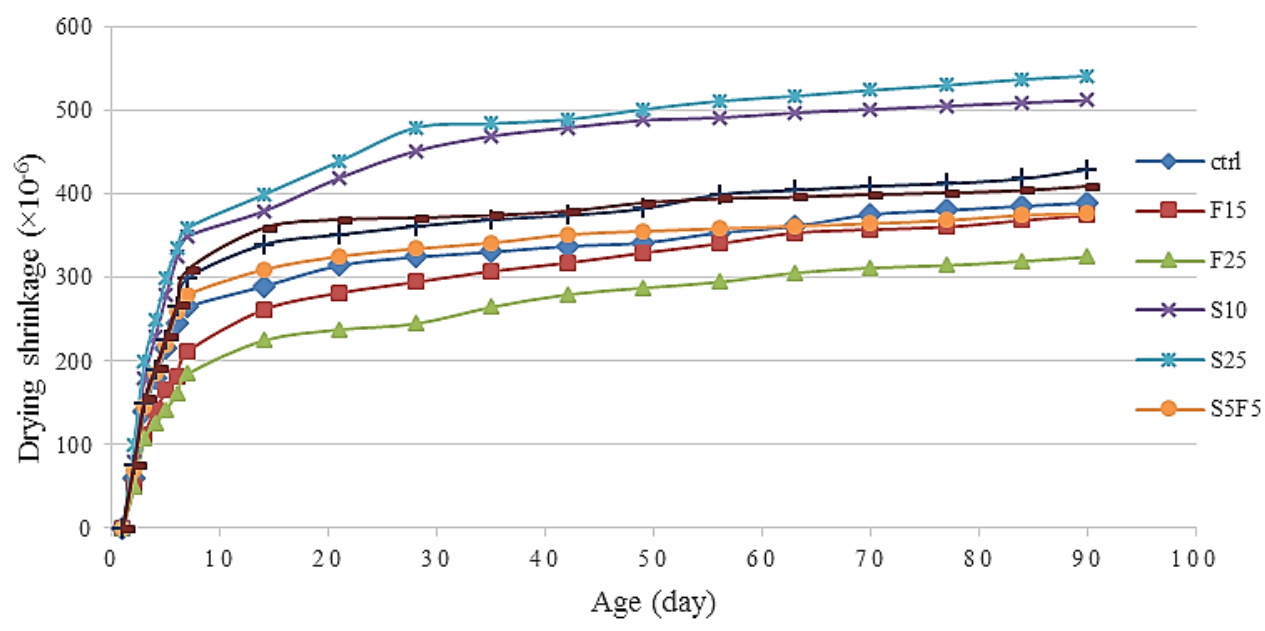

Figure 6. Drying shrinkage of concrete mixtures 


\section{Conclusion}

Evaluation of mechanical properties (compressive strength, flexural strength), final water absorption, morphology and drying shrinkage of concrete with silica fume and fly ash at different curing ages was presented in this paper. The following conclusions were extracted:

- Based on experiments, it can be concluded the silica fume have significant superiority to fly ash. Advantage of silica fume as a perfect pozzolan at least for the first 3 months of concrete age can be clearly concluded from the results. Also the high percentage of silica as a factor of impermeability in the fume and its active effect on reduction of lime and increasing the amount of C-S-H and concrete's structural compacting improvement make the silica fume an effective additive for concrete.

- The presence of pozzolanic material in concrete mixtures has been increased compressive and flexural strengths. The presence of silica in binary mixtures increases the strength of all ages. Fly ash in old age has a high compressive strength of the concrete is witnessed. In combine mixture minor pozzolanic materials increased resistance is also present.as well as addition of minerals pozzolanic reduced water absorption.

- Mineral admixtures can improve microstructure as well as compressive strength. Mineral admixtures enhance microstructure mainly results from micro aggregate filling and the pozzolanic effect, fine particles bridge the gaps between cement particles, hydration products, matrix and aggregates, so pore structure becomes denser.

- Addition of silica fume increased the drying shrinkage of concrete but using fly ash decreased it.

\section{References}

[1] Mostafa Jalal, Alireza Pouladkhan, Omid Fasihi Harandi, Davoud Jafari. "Comparative study on effects of Class F fly ash, nano silica and silica fume on properties of high performance self-compacting concrete". Construction and Building Materials 94 (2015) 90:104.

[2] Erhan Güneyisi, Mehmet Gesog`lu, Seda Karaog`lu, Kasım Mermerdas. "Strength, permeability and shrinkage cracking of silica fume and metakaolin concretes. Construction and Building Materials 34 (2012) 120:130.

[3] Navneet Chahal, Rafat Siddique. "Permeation properties of concrete made with fly ash and silica fume:Influence of ureolytic bacteria". Construction and Building Materials 49 (2013) 161:174.

[4] David O. Koteng, Chun-Tao Chen. "Strength development of lime-pozzolana pastes with silica fume and fly ash". Construction and Building Materials 84 (2015) 294:300.

[5] Chul-Woo Chung, Chang-Seon Shon, Young-Su Kim. "Chloride ion diffusivity of fly ash and silica fume concretes exposed to freeze-thaw cycles". Construction and Building Materials 24 (2010) 1739:1745.

[6] Liu Baoju, Xie Youjun, Zhou Shiqiong, Yuan Qianlian. "Influence of ultrafine fly ash composite on the fluidity and compressive strength of concrete". Cement and Concrete Research 30 (2000) 1489:1493.

[7] Alexander MG, Magee BJ. "Durability performance of concrete containing condensed silica fume". Cem Concr Res 1999;29:917-22.

[8] Khatri RP, Sirivivatnanon V, Yu LK. "Effect of curing on water permeability of concretes prepared with normal Portland cement and with slag and silica fume". Mag Concr Res 49(1997) 167:172.

[9] Ali Sadr momtazi, jalil barandoost, Behzad Tahmouresi, Mohammad Sadegh Tahmouresi. Mechanical evaluation of cementitious mortars containing fly ash and silica fume with smoothing spline interpolant: Proceedings of the Seventh Annual International Conference on Concrete Iran - Tehran (2014).

[10] Bhanja. S, Sengupta. B. "Influence of silica fume on the tensile strength of concrete". Cement and Concrete Research 35 (2005) 743:747.

[11] A. Bilodeau, V. Sivasundaram, K.E. Painter, V.M. Malhotra." Durability of concrete incorporating high volumes of fly ash from sources in US". ACI Mater. J. 91 (1994) 3:12.

[12] Joshi RC, Lohtia RP. Fly ash in concrete: production, properties and uses. Netherlands: Gordon and Breach Science Publishers; (1999).

[13]Han SH, Kim J-K, Park YD. Prediction of compressive strength of fly ash concrete. Cem Concr Res 33 (2003) 965:971.

[14] Gesoglu M, Ozbay E. "Effects of mineral admixtures on fresh and hardened properties of self-compacting concrete: binary, ternary and quaternary systems". Mater Struct 40 (2007) 923:937. 
[15] Katri RP, Sirivivatnanon V, Gross W. "Effect of different supplementary cementitious materials on mechanical properties of high performances concrete". Cem Concr Res 25 (1995) 209:920.

[16] Ali Sadr Momtazi, Ali Fasihi. The use of nano silica to improve the properties of composite cements containing silica fume: Proceedings of the 8th International Congress of Civil Engineering, Iran-Shiraz (2009).

[17] Jianyong L, Yan Y. A. "study on creep and drying shrinkage of high performance concrete". Cem Concr Res 31 (2001) 1203-1206.

[18] Hooton, R.D. "Influence of silica fume replacement of cement on physical properties and resistance to sulfate attack freezing and thawing, and alkali-silica reactivity". ACI Mater. J. 90(2) (1993) 143:152.

[19] Mohamed Abd Elrahman, Bernd Hillemeier. "Combined effect of fine fly ash and packing density on the properties of high performance concrete: An experimental approach". Construction and Building Materials 58 (2014) $225: 233$

[20] Sarıdemir M. "Effect of silica fume and ground pumice on compressive strength and modulus of elasticity of high strength concrete". Construction and Building Materials 49 (2013) 484:489.

[21] AppaRao G. "Long-term drying shrinkage of mortar-influence of silica fume and size of fine aggregate". Cem Concr Res 31 (2) (2001) 171:175. 